\title{
ESTRUTURAS VULCÂNICAS PRESERVADAS EM GRANULITOS DA SEQUÊNCIA VULCANO-SEDIMENTAR JUSCELÂNDIA, GO
}

\author{
CÉSAR F. FERREIRA FILHO, SYLVIA M. ARAÚJO \& HENRYETTE P. CRUZ
}

\begin{abstract}
PRESERVED VOLCANIC STRUTURES IN GRANULITES OF THE JUSCELANDIA VOLCANOSEDIMENTARY SEQUENCE, GO Granulite facies rocks of the volcanic-sedimentary sequences located to the west of the large layered intrusions of central Brazil are described for the first time in this paper. The granulite facies assemblage consists of $\mathrm{Cpx}+\mathrm{Opx}+\mathrm{Hbl}+\mathrm{PI}$ and are characterized by fine-grained granoblastic texture. Similar granulite facies assemblage characterize the west border of the northern segment of the Barro Alto Complex, suggesting progressive metamorphism through the contact between volcanic and plutonic domains.

Low strain zones preserve pillow lavas and relict phenocrysts of PI and Cpx within the granulite facies fine-grained granoblastic matrix. Relict phenocrysts of $\mathrm{Cpx}$ and $\mathrm{PI}$ have distinct chemical composition when compared with metamorphic $\mathrm{Cpx}$ and $\mathrm{PI}$. $\mathrm{Mg} / \mathrm{Mg}+\mathrm{Fe}$ and $\mathrm{Al}, \mathrm{Na}$, Ti, $\mathrm{Cr}$ contents are higher in the igneous Cpx when compared with metamorphic Cpx. An contents have values between 78.5 e 85.0 for igneous PI and between 41.5 e 58.9 for metamorphic PI. Distinct chemical compositions between igneous and metamorphic minerais indicate different physical conditions of crystallization for igneous and metamorphic minerais. The phenocryst assemblage is used to model fractional crystallization of the Juscelândia volcanic sequence and indicates an evolved basaltic volcanism.

Keywords: pillow lava, basalt, granulite, clinopyroxene, plagioclase, metamorphism, Barro Alto, Juscelândia, Brazil.

RESUMO A primeira ocorrência de granulitos pertencentes às sequências vulcano-sedimentares situadas à oeste dos grandes complexos acamadados do Brasil central é descrita neste trabalho. A paragênese granulítica consiste essencialmente de Cpx $+\mathrm{Opx}+\mathrm{Hbl}+\mathrm{PI}$ em um agregado granoblástico poligonal de grão fino. As paragêneses granulíticas do afloramento do Rio Pombal são idênticas àquelas observadas em rochas máficas da borda oeste do segmento NS do Complexo Barro Alto. Este fato indica condições de metamorfismo semelhantes para as rochas plutônicas da borda oeste do Complexo Barro Alto e para as rochas supracrustais adjacentes da faixa leste da Sequência Juscelândia, sugerindo a existência de um evento metamórfico progressivo similar ao descrito para a região de Niquelândia.

Faixas menos deformadas apresentam estruturas em lavas almofadadas parcialmente preservadas com eventuais fenocristais ígneos reliquiares de PI e Cpx. Os fenocristais reliquiares de Cpx e PI têm composição química distinta quando comparados com Cpx e PI metamórficos da matriz granoblásticá. A razão $\mathrm{Mg} / \mathrm{Mg}+\mathrm{Fe}$ e os teores de $\mathrm{Al}, \mathrm{Na}$, Ti e $\mathrm{Cr}$ são mais elevados no Cpx ígneo do que no Cpx metamórfico. O teor da molécula de An varia entre 78,5 e 85,0 no PI ígneo e entre 41,5 e 58,9 no PI metamórfico. As diferenças composicionais são justificadas pelas condições físicas de formação distintas dos fenocristais ígneos e dos minerais formados durante o evento metamórfico de alto grau. A identificação e determinação da composição química de fenocristais permite refinar os estudos litogeoquímicos, os quais indicam uma natureza fracionada para o vulcanismo basáltico da sequência Juscelândia.
\end{abstract}

Palavras-chaves: lavas almofadadas, basalto, granulito, clinopiroxênio, plagioclásio, metamorfismo, Barro Alto, Juscelândia, Brasil

INTRODUÇÃO A unidade basal da sequência vulcano-sedimentar Juscelândia (Danni et al. 1982) é constituída essencialmente por anfibolitos interpretados como rochas metavulcânicas máficas metamorfisadas na fácies anfibolito. Estruturas vulcânicas primárias foram identificadas em um único afloramento (denominado de afloramento do Rio Pombal) de rochas metamáficas da unidade basal da sequência vulcano-sedimentar Juscelândia durante os trabalhos de mapeamento geológico do Projeto Quebra Linha -Barro Alto (IGUnB, Relatórios de Graduaçã̃o de 1996). Estudos subsequentes mostraram que este afloramento se reveste de particular importância para o estudo das sequências vulcano-sedimentares mesoproterozóicas do Brasil central. $\mathrm{O}$ afloramento é a primeira ocorrência de paragênese granulítica em rochas indiscutivelmente pertencentes às sequências vulcano-sedimentares aflorantes à oeste dos grandes complexos máfico-ultramáficos de GO-TO. O afloramento fornece também os primeiros dados de química mineral de fenocristais pertencentes à estas sequências.

O objetivo deste trabalho é o de apresentar uma descrição geológica, petrográfica e petrológica das rochas metabásicas do Rio Pombal, discutindo a sua importância para o entendimento petrológico da sequência vulcano-sedimentar Juscelândia. Em particular, o trabalho apresenta resultados que corroboram o conceito de metamorfismo regional progressivo envolvendo os complexos acamadados e as sequências vulcano-sedimentares, originalmente apresentado por Ferreira Filho et al. $(1992,1994,1998)$ para a região de Niquelândia.

GEOLOGIA REGIONAL A figura 1 contém as principais unidades geotectônicas do Brasil central, cuja revisão estratigráfica e evolução geotectônica é apresentada por Fuck et al. (1994), e não será repetida no presente trabalho. Contudo; dois aspectos específicos, os quais são particularmente significativos para este trabalho, serão abordados a seguir. Estes incluem os grandes complexos acamadados e as sequências vulcano-sedimentares situadas à oeste destes complexos. As três grandes intrusões acamadadas do Brasil central (Cana Brava, Niquelândia e Barro Alto) constituem complexos estratiformes deformados e submetidos a metamorfismo de alto grau (Ferreira Filho et al. 1992). Dados U-Pb em zircões do Complexo Niquelândia (Ferreira Filho et al 1993, 1994) sugerem uma idade Mesoproterozóica (1560-1600 Ma) para o magmatismo. Contudo, idades mais antigas (i.e. $2000 \mathrm{Ma}$ ) para o evento magmático têm sido sugeridas por datações Rb-Sr e Sm-Nd no Complexo Cana Brava (Correia 1994, Correia et al 1997); bem como por datações U-Pb (SHRIMP) e Re-Os no Complexo Niquelândia (Correia et al. 1996). A par das várias datações atualmente disponíveis, as quais incluem diferentes meto-

* Instituto de Geociências - UnB, Brasília-DF, 70910-900, cesarf@ unb.br dologias, a idade da cristalização primária do magmatismo máfico ainda não está bem definida.

Dados U-Pb em zircões do Complexo de Niquelândia (Ferreira Filho et al. 1993, 1994) estabelecem o intervalo de 770-795 Ma para o metamorfismo de alto grau. A natureza progressiva desde o fácies anfibolito até o fácies granulito do evento metamórfico, incluindo tanto rochas do Complexo Niquelândia quanto rochas da sequência vulcanosedimentar Indaianópolis, foi inicialmente sugerida por Ferreira Filho et al (1992) e confirmada em trabalhos subsequentes (Ferreira Filho et al. 1994, 1998). O metamorfismo de alto grau foi correlacionado à um evento de colisão continental Neoproterozóico (Ferreira Filho \& Naldrett 1993). A extensão do evento metamórfico no intervalo de 770-795 Ma tem sido confirmada por datações subsequentes nos complexos Barro Alto (Suita et al 1996), Niquelândia (Correia et al 1996) e Cana Brava (Correia 1994, Correia et al 1997). Cabe salientar que Correia et al. (1997) consideram que o evento metamórfico-tectônico de alto grau afetando os complexos Barro Alto e Cana Brava tem idade de $1350 \mathrm{Ma}$, semelhante ao que havia sido anteriormente considerado por Fuck et al. (1989) para o Complexo Barro Alto.

As sequências vulcano-sedimentares formam um cinturão descontínuo de direção NE com cerca de $300 \mathrm{~km}$ de comprimento. O cinturão é constituído por três sequências fisicamente separadas (Palmeirópolis, Indaianópolis e Juscelândia) situadas na borda oeste dos complexos máfico-ultramáficos (Cana Brava, Niquelândia e Barro Alto, respectivamente). Datação $\mathrm{Pb}-\mathrm{Pb}$ em galenas do depósito vulcano-exalativo de Palmeirópolis indica uma idade entre 1170 e 1270 Ma para a sequência vulcano-sedimentar (Araújo 1996. Araújo et al 1996). Interpretações conflitantes têm sido apresentadas com relação à natureza do contato entre os complexos acamadados e as sequểncias vulcano-sedimentares. A maioria dos trabalhos de mapeamento geológico descrevem contatos tectônicos. Exemplos incluem os trabalhos de Fuck et al. (1981), Danni et al (1984) e o Projeto Barro Alto-Quebra Linha (inédito) para o contato entre o Complexo Barro Alto e a Sequência Juscelândia; o trabalho de Ferreira Filho et al (1992) para o contato entre o Complexo Niquelândia e a Sequência Indaianópolis; e os trabalhos de Leão Neto \& Olivatti (1983) e Lima (1997) para o contato entre o Complexo Cana Brava e a Sequência Palmeirópolis. A natureza intrusiva dos complexos acamadados nas sequências vulcano-sedimentares é descrita nos trabalhos de Girardi et al (1986) e Correia (1994).

A existência de interpretações conflitantes com relação à idade do principal evento tectônico-metamórfico do Brasil central, assim como da natureza do contato entre as rochas acamadadas e as sequências 
vulcano-sedimentares, constitui uma questão particularmente significativa para a evolução crustal do Precambriano do Brasil central. Estes aspectos serão retomados nas discussões do presente trabalho.

\section{GEOLOGIA E METAMORFISMO DO COMPLEXO BARRO} ALTO E SEQUÊNCIA JUSCELÂNDIA Uma síntese atualizada dos trabalhos anteriores desenvolvidos no Complexo Barro Alto e
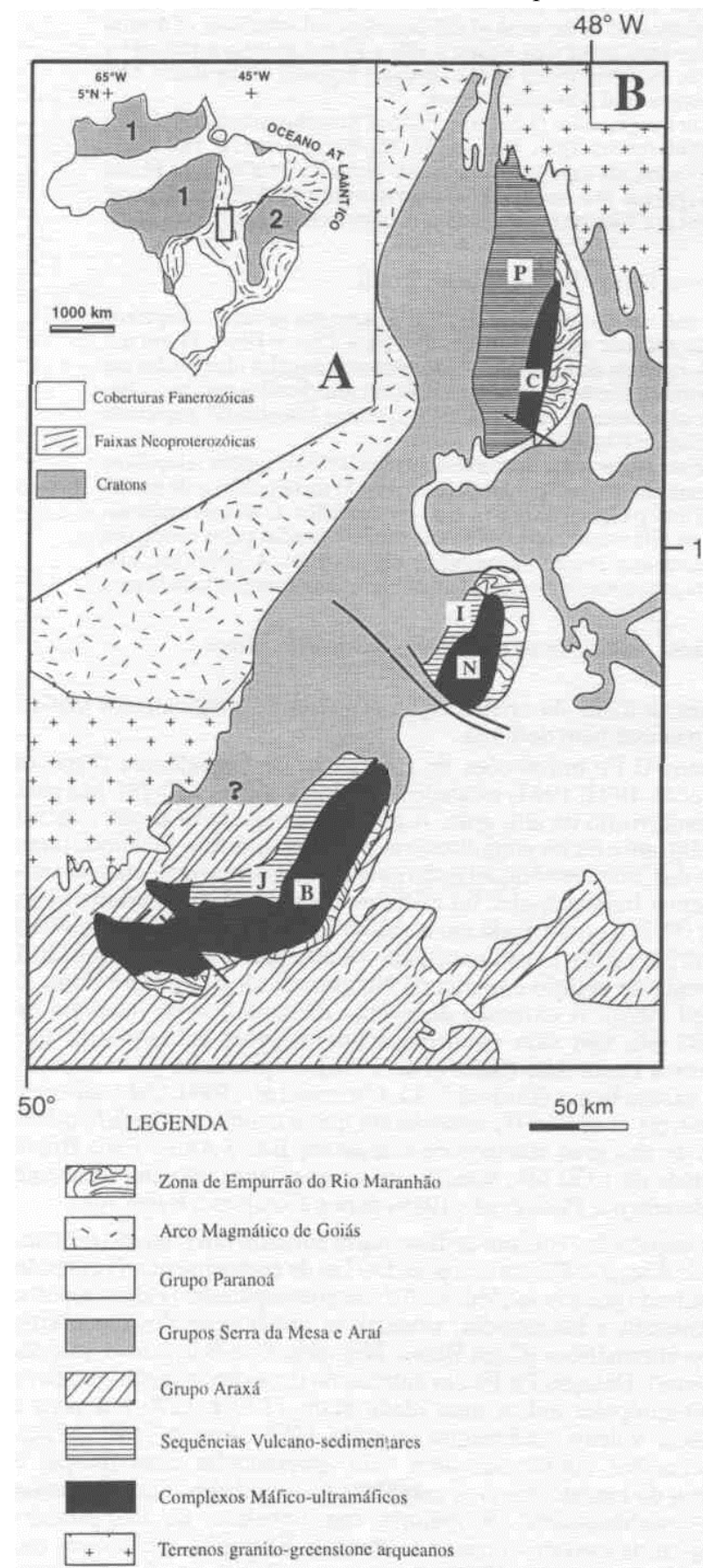

\footnotetext{
1 -Craton Ama/.ônico

2 -Craton do São Francisco

C-Complexo Cana Brava

N - Complexo Niquclândia

B - Complexo Barro Alto

P - Sequência Palmeirópolis

I - Sequência Indaianópolis

$\mathrm{J}$ - Sequência Juscelândia
}

Figura l - A) Principais unidades geotectônicas do Brasil (Fuck et al. 1994). A área delimitada está detalhada em B. B) Mapa geológico simplificado do Brasil central. Modificado de Danni et al. (1982), Marini et al. (1984) e Fuck et al. (1994).
Sequência Juscelândia é apresentada por Winge (1995) e Moraes (1997). O mapa geológico esquemático da figura 2 permite observar as principais unidades regionais do segmento norte do Complexo Barro Alto e da Sequência Juscelândia.

O Complexo Barro Alto é dividido em dois conjuntos de rochas infracrustais metamorfisadas: sequências Serra de Santa Bárbara e Serra da Malacacheta. A Sequência Serra de Santa Bárbara é constituída predominantemente por rochas máficas (metagabronorito, metagabro, metanorito) e ultramáficas acamadadas (metapiroxenito e metaperidotito). A Sequência Serra da Malacacheta é uma sequência essencialmente máfica com predomínio de gabro, olivina-gabro, troctolito e anortosito.

A Sequência Juscelândia (Fuck et al. 1981, Moraes 1992, 1997) consiste de quatro unidades: a unidade basal é constituída por anfibolito (metabasalto) com rochas metassedimentares químicas subordinadas, as duas unidades intermediárias são constituídas por biotita gnaisse (metagranitóides) e xisto feldspático e biotita-muscovita gnaisse (metavulcânicas ácidas) sobreposto, e a unidade de topo apresenta predomínio de metapelitos e metavulcânicas máficas e félsicas subordinadas. Moraes (1997), com base em dados litoquímicos, considera que o vulcanismo se deu em ambiente de rifte continental que possivelmente chegou a evoluir até a abertura de um oceano.

A natureza do metamorfismo e das relações de contato entre o Complexo Barro Alto e a Sequência Juscelândia têm sido interpretadas de diversas formas. Fuck et al. (1981), Danni et al. (1984), Fuck et al. (1989) e Winge (1995) consideram que as sequências Juscelândia e Serra da Malacacheta são co-magmáticas e mais jovens do que a Sequência Serra de Santa Bárbara. Segundo estes autores, existem dois eventos metamórficos cronologicamente distintos, sendo que o evento granulítico seria mais antigo e não teria afetado as sequências mais jovens. Uma evolução magmática comum para todo Complexo Barro Alto é defendida por Girardi et al. (1981) e Suita (1996). Suita (1996) apresenta dados $\mathrm{U}-\mathrm{Pb}$ em minerais demostrando que o evento metamórfico que afetou o Complexo Barro Alto e a Sequência Juscelândia tem idade entre 770 e 829 Ma. Moraes (1997), baseado em determinações termobarométricas desenvolvidas na região de Goianésia e Juscelândia, consideram que as rochas do Complexo Barro Alto foram metamorfisadas sob condições do fácies granulito e que as rochas da Sequência Juscelândia foram metamorfisadas sob condições do fácies anfibolito. Os dados termobarométricos indicaram ainda a existência de uma importante diferença entre o pico do metamorfismo calculado para a Sequência Juscelândia $\left( \pm 610^{\circ} \mathrm{C}\right.$ e $\left.5,5 \mathrm{kbar}\right)$ e o metamorfismo granulítico do Complexo Barro Alto $\left(900^{\circ} \mathrm{C}\right.$ e 8,5 kbar), diferença interpretada pelo autor como indicativa da supressão tectônica de parte da coluna geológica da região.

GEOLOGIA LOCAL O mapa geológico da área de afloramento das lavas almofadadas do Rio Pombal está representado na Figura 3, modificada à partir do Projeto Barro Alto-Quebra Linha (inédito). A Sequência Juscelândia ocorre em áreas arrasadas e com afloramentos

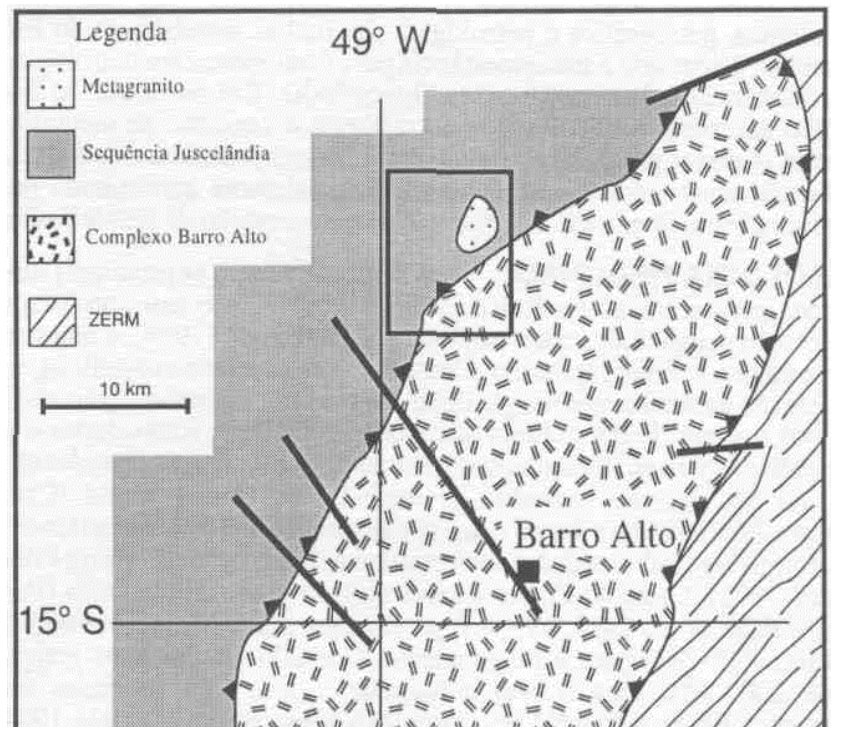

Figura 2 - Mapa geológico esquemático do segmento norte do Complexo Barro Alto e Sequência Juscelândia. A área delimitada está detalhada na Figura 3. ZERM - Zona de Empurrão do Rio Maranhão. 
descontínuos devido à presença de coberturas detrito-lateríticas. O Complexo Barro Alto ocorre em áreas de relevo acidentado e com afloramentos abundantes, representada na região pela Serra da Laguna. O contato entre a Sequência Juscelândia e o Complexo Barro Alto está geralmente encoberto, sendo caracterizado regionalmente como tectônico (falha de empurrão). O Complexo Barro Alto consiste de olivina gabro, troctolito e leucotroctolito transformados em anfibolito ou granulito máfico ao longo de faixas de deformação dúctil.

A Sequência Juscelândia nas proximidades do afloramento do Rio Pombal é representada por uma faixa de anfibolito fino, adjacente ao
Complexo Barro Alto, e uma faixa de metapelitos a oeste da primeira. Corpos de natureza ácida são interpretados como granitóides intrusivos e/ou sub-vulcânicos. A faixa de anfibolitos finos é correlacionada à unidade basal enquanto a faixa metapelítica é correlacionada à unidade de topo da Sequência Juscelândia conforme descrito por Moraes (1992).

$\mathrm{O}$ anfibolito tem granulação fina, foliação proeminente, estrutura maciça a levemente bandada e textura nematoblástica. É constituído essencialmente por hornblenda e plagioclásio com titanita e quartzo como acessórios frequentes. Os metassedimentos são mica xistos

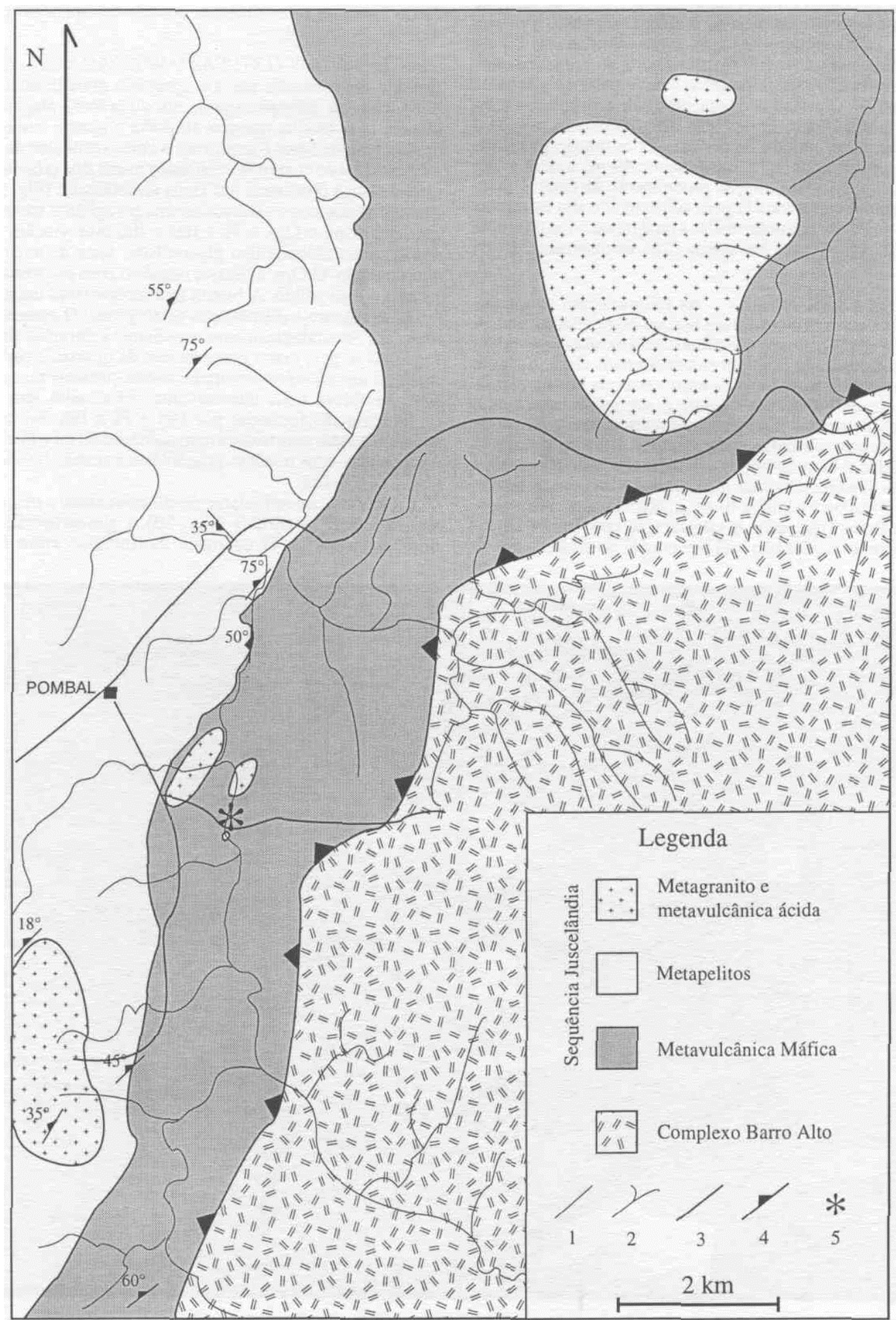

Figura 3 - Mapa geológico esquemático da área do afloramento com lavas almofadadas do rio Pombal. Modificado do Projeto Barro Alto-Quebra Linha. $l$ = estrada; 2 = rios e córregos; 3 = contato geológico; 4 = falha de empurrão; 5 = afloramento do rio Pombal. 
(quartzo-muscovita xisto, clorita-quartzo-muscovita xisto, muscovitaquartzo xisto) fortemente intemperizados e com raras intercalações quartzosas. As rochas ácidas têm granulação média, estrutura gnássica e são constituídas por microclina, quartzo, plagioclásio com moscovita, biotita, zircão e apatita como acessórios frequentes.

\section{Afloramento com lavas almofadadas do rio Pombal $\mathrm{O}$}

acesso ao afloramento com lavas almofadadas é feito por estrada de terra à partir do Povoado de Placa que fica às margens da rodovia que liga Uruaçu a Barro Alto. À partir de Placa segue-se $5 \mathrm{~km}$ rumo NE até o local conhecido como Pombal (indicado na Fig. 3). À partir de Pombal o acesso é feito por estradas de fazendas (seguindo o roteiro indicado na Fig. 3). $\mathrm{O}$ afloramento com lavas almofadadas do rio Pombal está situado a cerca de 100 metros à norte da ponte indicada na figura 3. A localização do afloramento é dada pelas coordenadas $716830 \mathrm{E}$ e $8361089 \mathrm{~N}$. O período de seca, especialmente julho-setembro, é o melhor período para observação do afloramento, o qual é parcialmente coberto no período de chuvas. As estruturas primárias estão restritas à uma área de aproximadamente $40 \mathrm{~m}$ a qual grada lateralmente para rochas com foliação proeminente de direção geral NE. Esta orientação é caracterizada pela achatamento das estruturas almofadadas nas zonas menos deformadas a qual transiciona para uma foliação tectônica proeminente nas zonas mais intensamente deformadas.

DESCRIÇAO DAS ESTRUTURAS As estruturas em almofadas ocorrem em rochas escuras de estrutura maciça e granulação fina. A individualização destas estruturas é facilitada pela existência de material interpillow caracterizado por uma coloração mais clara. As lavas almofadadas apresentam forma e dimensão variáveis em função de diferentes taxas de deformação. A forma é sempre achatada com aspecto elipsoidal. Estruturas maiores apresentam cerca de $30 \mathrm{~cm}$ de diâmetro, estão menos achatadas e têm contato entre as diferentes estruturas almofadadas bem definidos pelo material interpillow (Figs 4A-B). Estruturas menores são mais alongadas e com aspecto boudinado, devendo corresponder à uma fragmentação tectônica de estruturas originais maiores (Fig. 4C). A estruturação concêntrica característica de lavas almofadadas não está preservada no afloramento. $\mathrm{O}$ arranjo entre estruturas almofadadas com indicação de topo e base de derrame também não está caracterizado no afloramento. A não preservação destas estruturas, assim como o seu achatamento generalizado, indica uma deformação parcial das estruturas primárias. Por outro lado, existem algumas estruturas almofadadas que apresentam textura porfirítica com fenocristais de plagioclásio e piroxênio com até $0,5 \mathrm{~cm}$ de diâmetro (Fig. 4D). Rochas com textura porfirítica original estão restritas à uma pequena faixa com menos do que 1 metro de espessura. Nas porções mais deformadas ocorre a gradação para rochas com foliação proeminente e um bandamento pouco pronunciado. Nestas faixas ocorrem remobilizados quartzo-feldspáticos que obliteram a morfologia original.

DESCRIÇÃO DAS TEXTURAS E MINERALOGIA As rochas almofadadas são formadas por um agregado granoblástico com contatos poligonais de clinopiroxênio, ortopiroxênio, plagioclásio e hornblenda, com biotita, quartzo, ilmenita e apatita como acessórios. A textura granoblástica é interpretada como resultante da recristalização metamórficade uma rocha vulcânica muito fina (afanítica?). A textura granoblástica observada nas lavas almofadadas (Fig. 5A) é típica de granulitos máficos e caracteriza uma paragênese metamórfica de alto grau com Cpx + Opx + PI + Hbl \pm Ilm (abreviações segundo Kretz 1983). A hornblenda tem pleocroísmo forte de amarelo a castanho avermelhado. O Opx é biaxial negativo com pleocroísmo distinto de incolor a rosa pálido. A biotita tem pleocroísmo intenso de incolor a vermelho escuro e distribuição heterogénea. $\mathrm{O}$ material interpillow é textural e mineralogicamente semelhante à estrutura almofadada, distinguindo-se pela maior percentagem de quartzo e carbonatos. A turmalina é um acessório esporadicamente presente no material interpillow. As faixas mais intensamente deformadas têm textura nematoblástica e são formadas por $\mathrm{Hbl}+\mathrm{PI} \pm \mathrm{Ilm}$. Em zonas bandadas ocorrem bandas com textura nematoblástica $(\mathrm{Hbl}+\mathrm{PI} \pm \mathrm{Ilm})$ alternadas com bandas com texturas granoblástica nematoblástica $(\mathrm{Hbl}+\mathrm{PI}+$ $\mathrm{Cpx} \pm \mathrm{Opx} \pm \mathrm{Ilm})$

Os fenocristais reliquiares de clinopiroxênio e plagioclásio preservam a textura porfirítica (Fig. 5B) a glomeroporfirítica (Fig. 5C) original da rocha. $\mathrm{O}$ contraste morfológico entre fenocristais re-

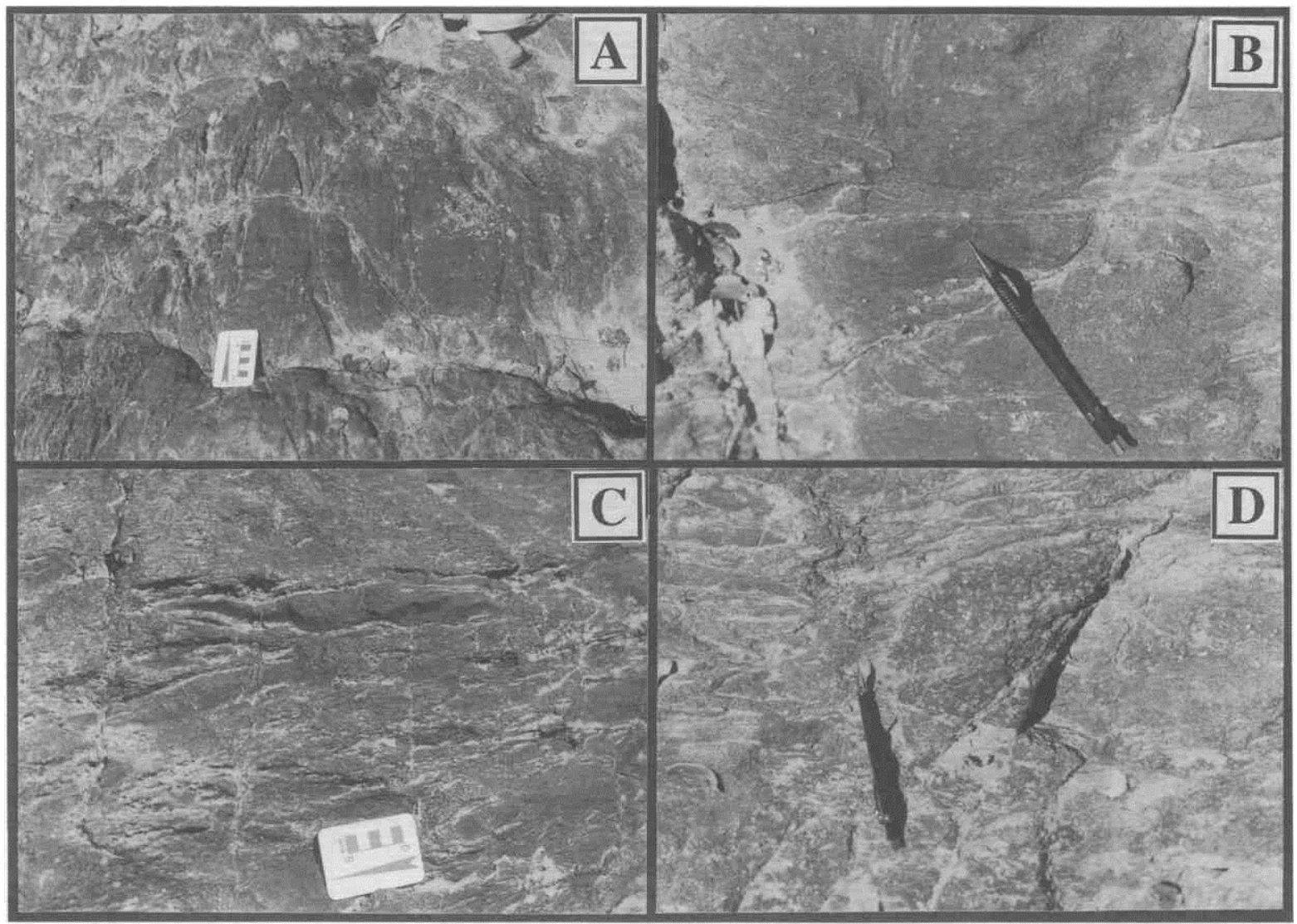

Figura 4 - (A) Aspecto geral das estruturas almofadas e material interpillow. (B) Detalhe do material interpillow. (C) Estruturas almofadadas menores e relativamente mais alongadas e achatadas. (D) Estruturas almofadadas com fenocristais reliquiares. Notar os fenocristais de plagioclásio de coloração esbranquiçada. 
liquiares e a matriz granoblástica fina é marcante. Os fenocristais têm hábito euédrico e eventualmente apresentam faces corroídas e/ou golfos de corrosão. Existem cristais que ainda preservam delicadas zonações primárias (Fig. 5B-D). Os efeitos de deformação e recristalização metamórfica são heterogéneos com domínios nos quais os fenocristais estão totalmente recristalizados.

COMPOSIĈ̃O QUÍMICA DOS MINERAIS Análises químicas dos minerais foram realizadas no Laboratório de Microssonda Eletrônica do Instituto de Geociências da Universidade de Brasília (CAMECA SX 50). Análises quantitativas foram realizadas utilizando voltagem de $15 \mathrm{kV}$, corrente de $25 \mathrm{nA}$ e condições experimentais ajustadas para cada tipo de mineral analisado. Análises semi-quantitativas por EDS (energy dispersive system) foram rotineiramente realizadas com objetivo de auxiliar os trabalhos de petrografia e otimizar as análises quantitativas, sendo particularmente útil para distinguir opx e cpx na matriz granoblástica fina.

Estudos quantitativos sistemáticos (cerca de 100 análises) restringiram-se ao clinopiroxênio e ao plagioclásio, minerais que ocorrem tanto como fenocristais primários reliquiares quanto na matriz granoblástica de origem metamórfica. O objetivo destes estudos é o de caracterizar a composição distinta entre as fases ígneas e metamórficas e de estabelecer a composição dos fenocristais reliquiares para utilização em modelamentos petrológicos.

Clinopiroxênio Análises representativas de clinopiroxênio ígneo e metamórfico estão ilustradas na Tabela 1 . O Cpx tem composição típica de piroxênios quadriláteros (En-Fs-Di-Hd) sendo constituído essencialmente pelas moléculas de En, Fs e Wo. Cpx ígneo reliquiar e cpx metamórfico têm composições marcadamente distintas. A Tabela 1 e a Figura 6 ilustram as diferenças composicionais entre Cpx ígneo e metamórfico.

As principais substituições observadas nos clinopiroxênios ígneos e metamórficos do rio Pombal estão representadas na figura 6. O Cpx metamórfico tem substituições mais restritas do que o Cpx ígneo. A substituicão representada pelo vetor de troca FeMg., indica uma direção distinta do vetor para Cpx ígneo e metamórfico (Fig. 6A). Este fato é significativo uma vez que demonstra que Cpx ígneo e metamór- fico evoluem em direcões distintas no espaco composicional. $\mathrm{O}$ vetor de troca $\mathrm{NaAl}^{\mathrm{IV}} \mathrm{Ca}_{-1} \mathrm{iMg}_{-1}$ (substituição jadeíta) indica substituições muito restritas para o $\mathrm{Cpx}$ metamórfico mas significativas para o $\mathrm{Cpx}$ ígneo (Fig. 6B). A figura 6B reflete os teores mais elevados de $\mathrm{Al}_{2} \mathrm{O}_{3}$ e $\mathrm{Na}_{2} \mathrm{O}$ do Cpx ígneo quando comparado com o Cpx metamórfico. O vetor de troca $\mathrm{Al}^{\mathrm{TV}} \mathrm{Al}^{\mathrm{IV}} \mathrm{Mg}_{-1} \mathrm{Si}_{-1}$ (substituição tschermak) indica também substituições restritas para o Cpx metamórfico mas significativas para o Cpx ígneo (Fig. 6C). A Fig. 6C reflete os teores mais elevados de $\mathrm{Al}_{2} \mathrm{O}_{3}$ do Cpx ígneo quando comparado com o Cpx metamórfico. Os teores de Ti e Cr são marcadamente mais elevados no Cpx ígneo do que no Cpx metamórfico (Tabela 1).

Estudos sistemáticos (i.e. seções composicionais) voltados para o estudo de possíveis zonações nos fenocristais de Cpx não foram realizados. A alteração e recristalização frequente dos fenocristais, especialmente nas bordas, dificulta a realização de seções completas. Análises esporádicas realizadas nas bordas dos fenocristais indicam composições semelhantes às obtidas no centro dos cristais com uma tendência a teores de En menores.

As diferenças composicionais são justificadas por condições físicas de formação distintas entre o Cpx ígneo e o Cpx metamórfico. Os fenocristais representam as fases liquidus existentes durante o evento de extravasamento do magma. Representam portanto cristais intratelúricos (Cox et al. 1979) cristalizados em profundidade em um período de residência do magma em uma câmara magmática anterior ao vulcanismo. São minerais formados à partir da cristalização direta de um líquido silicático e sua composição reflete as condições físicas e a composição do magma à partir do qual eles se cristalizam. Estes cristais portanto formaram-se à temperaturas magmáticas. Este fato justifica tanto a razão $\mathrm{Mg} / \mathrm{Mg}+\mathrm{Fe}$ relativamente mais elevada, indicado pelo teor da molécula de En mais elevado, assim como os teores mais elevados de $\mathrm{Al}, \mathrm{Ti}, \mathrm{Cr}$ e Na. Os cristais metamórficos representam o processo de cristalização no estado sólido de uma paragênese de alto grau. Estes cristais formaram-se a temperaturas inferiores quando comparado com o cristais ígneos, justificando tanto os teores menores da molécula de En como as substituições mais restritas nos sítios tetraédricos e octaédricos.

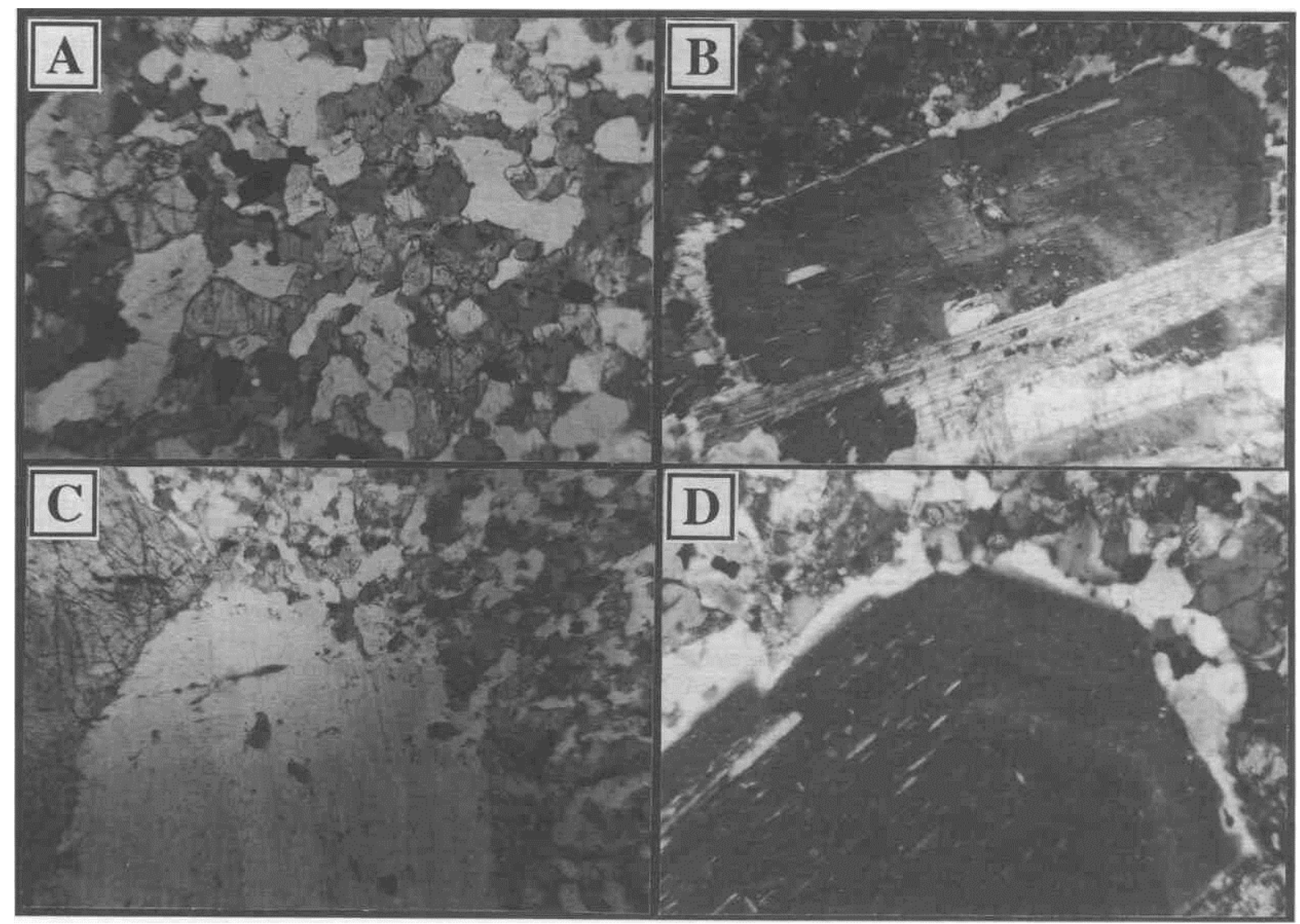

Figura 5 - (A) Granulito máfico $(O p x+C p x+P I+H b l \pm I l m)$ com textura granoblástica. (B) Fenocristal reliquiar euédrico de plagioclásio. Notar zonação e recristalização parcial do fenocristal. (C) Fenocristais reliquiares de clinopiroxênio e plagioclásio em textura glomeroporfiritica. (D) Detalhe da zonação em fenocristal reliquiar de plagioclásio. 
Tabela l - Análises representativas de clinopiroxênio ígneo e metamórfico do afloramento do rio Pombal.

\begin{tabular}{|c|c|c|c|c|c|c|c|c|c|c|c|c|}
\hline & 1B $1-1.1$ & $1 \mathrm{~B} 1-1.4$ & $1 \mathrm{~B} 2-1.2$ & $1 \mathrm{~B} 2-1.4$ & $1 \mathrm{~B} 2-1.6$ & $1 \mathrm{~B} 2-1.7$ & JPLIb-3.1.1 & JPL1b-3.2.2 & JPLIb-3.3.2 & $2 \mathrm{JPL} 1 \mathrm{~b}-10.2$ & JPLIb-13.1 & JPLIb-15.1 \\
\hline & I & I & 1 & I & I & I & M & M & M & M & M & $M$ \\
\hline $\mathrm{SiO2}$ & 50,99 & 51,63 & 52,69 & 50.87 & 52,37 & 50,68 & 52,74 & 52,64 & 52,87 & 52,77 & 52,61 & 52,96 \\
\hline TiO2 & 0,35 & 0,34 & 0,18 & 0,49 & 0,28 & 0,57 & 0,10 & 0,16 & 0,07 & 0,13 & 0,17 & 0,11 \\
\hline $\mathrm{A} 1203$ & 2,96 & 2,47 & 2,14 & 3,62 & 2,18 & 4,06 & 1,09 & 1,00 & 1,20 & 1,18 & 0,91 & 1,12 \\
\hline $\mathrm{Cr} 2 \mathrm{O}^{2}$ & 0,28 & 0,31 & 0,43 & 0,53 & 0,42 & 0,55 & 0,01 & 0,04 & $>$ & 0,03 & 0,01 & 0,05 \\
\hline $\mathrm{Fe} 2 \mathrm{O}$ & 2,04 & 0,86 & $>$ & 1,80 & 0,19 & 1,91 & $>$ & $>$ & $>$ & $>$ & 0,06 & $>$ \\
\hline $\mathrm{MgO}$ & 12,58 & 12,54 & 13,33 & 13,34 & 13,60 & 13,20 & 12,43 & 12,38 & 12,59 & 12,51 & 12,67 & 12,91 \\
\hline $\mathrm{CaO}$ & 20,78 & 20,87 & 21,77 & 19,97 & 21,06 & 19,60 & 22,20 & 21,75 & 22,36 & 22,38 & 22,16 & 22,39 \\
\hline MnO & 0,29 & 0,28 & 0,28 & 0,22 & 0,30 & 0,27 & 0,34 & 0,37 & 0,30 & 0.31 & 0,36 & 0,32 \\
\hline $\mathrm{FeO}$ & 8,33 & 9,28 & 8,03 & 7,21 & 8,28 & 7,58 & 10,21 & 10,99 & 9,54 & 9,95 & 10,41 & 9,41 \\
\hline $\mathrm{Na} 2 \mathrm{O}$ & 0,65 & 0,61 & 0,53 & 0,81 & 0,56 & 0,83 & 0.40 & 0,28 & 0,38 & 0,35 & 0,27 & 0,37 \\
\hline $\mathrm{K} 2 \mathrm{O}$ & 0,20 & 0,18 & 0,06 & 0.22 & 0,15 & 0.25 & $>$ & $>$ & $>$ & $>$ & $>$ & $>$ \\
\hline TOTAL & 99,45 & 99,38 & 99,43 & 99,13 & 99,43 & 99,51 & 99,54 & 99,63 & 99,31 & 99,63 & 99,65 & 99,69 \\
\hline
\end{tabular}

\begin{tabular}{|c|c|c|c|c|c|c|c|c|c|c|c|c|}
\hline \multicolumn{13}{|c|}{ Cátions normalizados a 6 oxigênios } \\
\hline Si IV & 1,92 & 1,95 & 1,97 & 1,91 & 1,96 & 1,90 & 1,99 & 1,99 & 1,99 & 1,99 & 1,98 & $1, \overline{99}$ \\
\hline Al IV & 0,08 & 0,05 & 0,03 & 0,09 & 0,04 & 0,10 & 0,01 & 0,01 & 0,01 & 0,01 & 0,02 & 0,01 \\
\hline T site & 2,00 & 2,00 & 2,00 & 2,00 & 2,00 & 2,00 & 2,00 & 2,00 & 2,00 & 2,00 & 2.00 & 2,00 \\
\hline Al VI & 0,05 & 0,06 & 0,07 & 0,07 & 0,05 & 0,07 & 0,04 & 0,04 & 0,05 & 0,04 & 0,02 & 0,04 \\
\hline $\mathrm{Ti}$ & 0,01 & 0,01 & 0,01 & 0,01 & 0,01 & 0,02 & 0,00 & 0,00 & 0,00 & 0,00 & 0,00 & 0,00 \\
\hline $\mathrm{Cr}$ & 0,01 & 0,01 & 0,01 & 0,01 & 0,01 & 0,02 & 0,00 & 0,00 & 0,00 & 0,00 & 0,00 & 0,00 \\
\hline $\mathrm{Fe}+3$ & 0,06 & 0,02 & 0,00 & 0,05 & 0,01 & 0,05 & 0,00 & 0,00 & 0,00 & 0,00 & 0,00 & 0,00 \\
\hline $\mathrm{Fe}+2$ & 0,26 & 0,29 & 0,25 & 0,23 & 0,26 & 0,24 & 0,32 & 0,35 & 0,30 & 0,31 & 0,33 & 0,30 \\
\hline $\mathrm{Mn}$ & 0,01 & 0,01 & 0,01 & 0,01 & 0,01 & 0,01 & 0,01 & 0,01 & 0,01 & 0,01 & 0,01 & 0.01 \\
\hline $\mathrm{Mg}$ & 0.71 & 0,70 & 0.74 & 0,75 & 0,76 & 0,74 & 0,70 & 0,70 & 0.71 & 0,70 & 0,71 & 0,72 \\
\hline $\mathrm{Ca}$ & 0,84 & 0,84 & 0,87 & 0,80 & 0,84 & 0,79 & 0,90 & 0,88 & 0,90 & 0,90 & 0,90 & 0,90 \\
\hline $\mathrm{Na}$ & 0,05 & 0,04 & 0,04 & 0,06 & 0,04 & 0,06 & 0,03 & 0,02 & 0,03 & 0,03 & 0,02 & 0,03 \\
\hline$K$ & 0,01 & 0,01 & 0,00 & 0,01 & 0.01 & 0,01 & 0,00 & 0,00 & 0,00 & 0,00 & 0,00 & 0,00 \\
\hline M1,M2 & 2,00 & 2,00 & 2,00 & 2,00 & 2,00 & 2,00 & 2,00 & 2,00 & 2,00 & 2,00 & 2,00 & 2,00 \\
\hline En & 39 & 38 & 40 & 42 & 41 & 42 & 36 & 36 & 37 & 36 & 37 & 37 \\
\hline Fs & 15 & 16 & 14 & 13 & 14 & 14 & 17 & 19 & 16 & 17 & 17 & 16 \\
\hline Wo & 46 & 46 & 46 & 45 & 45 & 44 & 47 & 45 & 47 & 47 & 46 & 47 \\
\hline
\end{tabular}

$\mathrm{I}=$ cpx ígneo; $\mathrm{M}$ = cpx metamórfico; > valor abaixo do limite de detecção.

Plagioclásio Análises representativas de plagioclásio ígneo e metamórfico estão ilustradas na Tabela 2. Plagioclásio ígneo reliquiar e plagioclásio metamórfico têm composições marcadamente distintas. A Tabela 2 e a Figura 7 ilustram as diferenças composicionais entre plagioclásio ígneo e metamórfico. O teor da molécula de An varia entre 78,5 e 85,0 no plagioclásio ígneo (média de 82,1), e entre 41,5 e 58,9 no plagioclásio metamórfico (média de 48,1). Os teores de FeO e K2O são muito baixos nos plagioclásios ígneos e mais elevados nos plagioclásios metamórficos. Os teores de $\mathrm{BaO}$ e $\mathrm{SrO}$ estão abaixo do limite de detecção e não são reportados na Tabela 2.

As diferenças composicionais são justificadas por condicões físicas de formação distintas entre plagioclásio ígneo e o plagioclásio metamórfico. Os mesmos princípios apresentados para as diferenças composicionais entre Cpx ígneo e metamórfico são aplicáveis ao plagioclásio. Os teores de An mais elevados para o plagioclásio ígneo são justificados pela temperatura de cristalização marcadamente mais elevada.

DISCUSSÃO O afloramento do Rio Pombal permite avançar o conhecimento em relação à três temas: i) a preservação local de estruturas e texturas primárias em terrenos metamórficos de alto grau; ii) as implicações regionais da caracterização de paragêneses granulíticas na Sequência Juscelândia; e iii) as implicações para o fracionamento da Sequência Juscelândia decorrentes da caracterização química dos fenocristais reliquiares.

Preservação de texturas e estruturas primárias em terrenos de alto grau $A$ existência de estruturas e texturas primárias preservadas em terrenos de alto grau é comum em determinados tipos de metamorfismo regional. Entre eles destacam-se os terrenos do tipo LPHT (low pressure high temperature terranes) os quais são ilustrados pêlos terrenos metamórficos do Arunta Block na região central da Austrália (Collins \& Vernon 1991). Em terrenos metamórficos de alto grau com pressões intermediárias a altas as
Tabela 2 - Análises representativas de plagioclásio ígneo e metamórfico do afloramento do rio Pombal.

\begin{tabular}{|c|c|c|c|c|c|c|c|c|c|c|c|c|}
\hline & $\frac{\text { I }}{1.1 .18}$ & $\begin{array}{l}I \\
1.3 .1\end{array}$ & 1.34 & $\begin{array}{c}1 \\
1.3 .7\end{array}$ & $\begin{array}{c}I \\
3.1 .2\end{array}$ & $\begin{array}{c}1 \\
3.1 .4\end{array}$ & $\begin{array}{l}\mathrm{M} \\
\text { I.I.3 }\end{array}$ & $\begin{array}{l}M \\
1.4 .2\end{array}$ & $\begin{array}{c}M \\
2.1 .1\end{array}$ & $\begin{array}{l}M \\
3.2 .1\end{array}$ & $\begin{array}{c}M \\
3.2 .2\end{array}$ & $\begin{array}{c}\mathbf{M} \\
0,4\end{array}$ \\
\hline $\mathrm{SiO}_{2}$ & 48,30 & 47,75 & 47,89 & 47,38 & 48,63 & 47,65 & 56,92 & 56,94 & 56.18 & 57,77 & 57,41 & 56,95 \\
\hline $\mathrm{A} 1203$ & 32,72 & 33,63 & 33.20 & 33,58 & 33,06 & 33.74 & 27,44 & 27,12 & 27,92 & 27,36 & 27,26 & 27,15 \\
\hline $\mathrm{CaO}$ & 16,03 & 16,93 & 16,10 & 16,83 & 15,89 & 16.54 & 9,46 & 9,35 & 9,94 & 9,03 & 9,16 & 9,02 \\
\hline $\mathrm{FeO}$ & 0,03 & 0,04 & 0,11 & 0,05 & 0,05 & 0,05 & 0,12 & 0,12 & 0.13 & 0,17 & 0,11 & 0,07 \\
\hline $\mathrm{Na} 2 \mathrm{O}$ & 2,06 & 1,71 & 1,91 & 1,72 & 2,01 & 1,72 & 5,44 & 5,60 & 5,18 & 5,67 & 5,63 & 5,75 \\
\hline $\mathbf{K} 20$ & 0,03 & 0,03 & 0,05 & 0,02 & 0,03 & 0,03 & 0,12 & 0,12 & 0,11 & 0,10 & 0,13 & 0,14 \\
\hline TOTAL & 99,26 & 100,13 & $99, \overline{35}$ & 99,57 & 99,76 & 99,81 & 99.59 & 99,32 & 99.53 & 100,13 & 99,85 & 99,23 \\
\hline $\mathbf{A b}$ & 18,8 & 15,3 & 17,7 & 15,6 & 18,6 & 15,8 & 50,6 & 51.7 & 48,2 & 52,8 & 52.2 & 53,1 \\
\hline$O_{T}$ & 0,2 & 0,2 & 0,3 & 0,1 & 0,2 & 0,2 & 0,7 & 0,7 & 0,7 & 0,6 & 0,8 & 0,9 \\
\hline An & 81,0 & 84,5 & 82,0 & 84,3 & 81,2 & 84,0 & 48,7 & 47.6 & 51,1 & 46,5 & 47,0 & 46,0 \\
\hline
\end{tabular}

I = Plagioclá sio ígneo; $\mathrm{M}=$ Plagioclásio meumórfico, $>$ valor abaixo do limite de deteccão.

estruturas, texturas e minerais primárias são frequentemente preservadas em rochas plutônicas máfico-ultramáficas. Estas rochas apresentam características estruturais/texturais (granulação grosseira, estrutura isotrópica) e químico/mineralógicas (rochas anidras, mineralogia de alta temperatura) que favorecem a sua preservação em condições de metamorfismo de alto grau à uma baixa pressão de $\mathrm{H} 2 \mathrm{O}$. Esta situação é bem ilustrada nos grandes complexos acamadados do Brasil central (Ferreira Filho et. 1992, 1998). De fato, os terrenos metamórficos de alto grau do Brasil central mostram um forte contraste entre a preservação frequente de feições primárias nas rochas plutônicas (complexos acamadados) e sua raridade nas rochas supracrustais (sequências vulcano-sedimentares). Uma vez que complexos acamadados e sequências vulcano-sedimentares do Brasil central foram submetidos ao mesmo evento metamórfico de alto grau, esta diferença reflete apenas o comportamento distinto de rochas plutônicas e supracrustais frente aos processos tectono-metamórficos. Embora esta observação represente algo trivial nos estudos de petrologia 

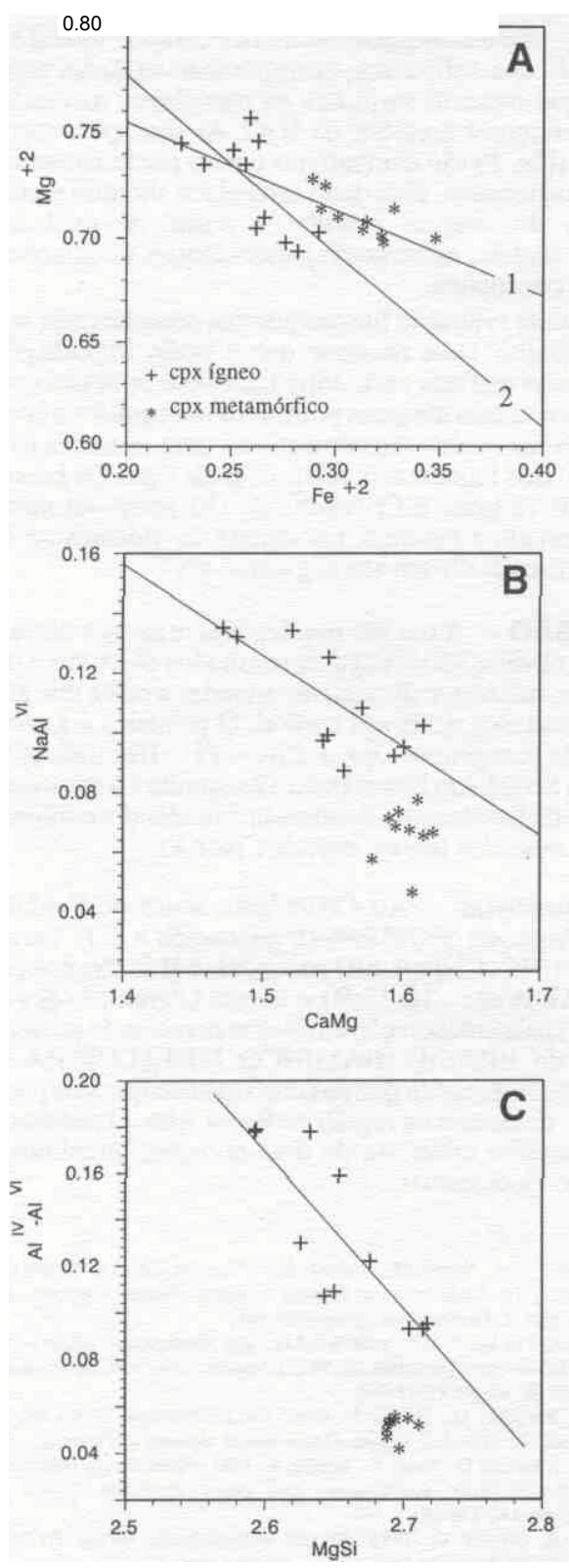

Figura 6 - Diagramas mostrando as principais substituições (vetares de trocas) dos clinopiroxênios ígneos e metamórficos do afloramento do rio Pombal. A) $\mathrm{MgF}_{-1}$ i. B) $\mathrm{NaAl}^{V I} \mathrm{Ca}_{-1} \mathrm{Mg}-1$ (jadeita) C) $\mathrm{Al}^{I^{-}}$ ${ }^{V} A^{V I} l \mathrm{Mg}_{-} j \mathrm{j} \mathrm{Si}_{-1}$ (Ca-tschermak ou Cats). $l=$ regressão linear para $o$ Cpx metamórfico. 2 = regressão linear para o Cpx ígneo.

metamórfica, sendo didaticamente apresentada por diversos autores (Passchier et al. 1990 é um bom exemplo) ela têm gerado algum desentendimento no centro-oeste (vide GEOLOGIA REGIONAL).

$\mathrm{O}$ afloramento do Rio Pombal apresenta duas particularidades que estão geneticamente relacionadas. As rochas do afloramento constituem tanto um caso raro de preservação de feições primárias nas rochas vulcânicas da unidade basal da Sequência Juscelândia, como a única ocorrência de paragênese granulítica nas sequências vulcano-sedimentares situadas à oeste dos complexos acamadados. Esta coincidência pode ser justificada por condições localizadas de $\mathrm{P}_{\mathrm{H} 20}$ relativamente mais baixa. Uma menor pressão de $\mathrm{H}_{2} \mathrm{O}$ dificulta o desenvolvimento de feições tectônicas dúcteis e consequentemente favorece a preservação de estruturas e texturas primárias. Paralelamente, uma menor $\mathrm{P}_{\mathrm{H} 20}$ favorece a estabilização de paragêneses anidras. A existência muito localizada da paragênese com Opx $+\mathrm{Cpx}+\mathrm{PI}+\mathrm{Hbl}$, em contraste com a existência conspícua de paragênese à base de $\mathrm{Hbl}+$ PI, pode ser explicada pela presença localizada de $\mathrm{P}_{\mathrm{H} 20}$ relativamente menores. De fato, as paragêneses distintas, respectivamente consideradas como diagnosticas de condições do fácies granulito e anfibolito

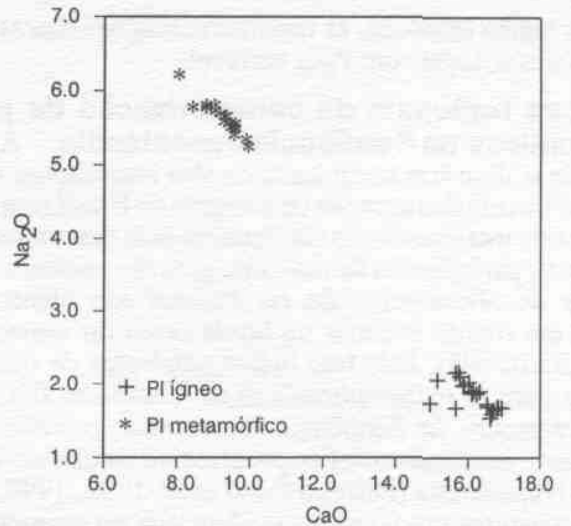

Figura 7 - Diagrama $\mathrm{Na}_{2} \mathrm{O}-\mathrm{CaO}$ para plagioclásios ígneos e metamórficos do afloramento do rio Pombal.
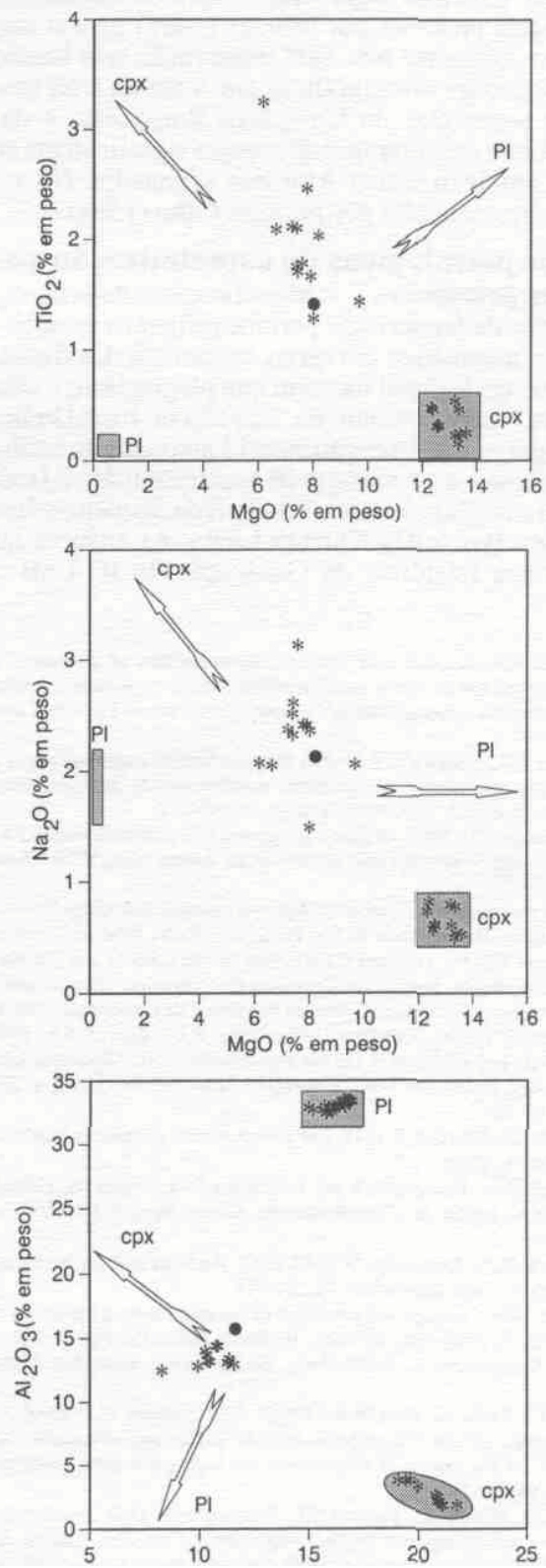

Figura 8 - Diagramas de variação para as rochas metavulcânicas máficas da Sequência Juscelândia. ${ }^{*}=$ Anfibolito. Círculo cheio $=$ granulito máfico (metavulcânica com estrutura almofadada do rio Pombal). A setas indicam os trenas de racionamento decorrentes dos fenocristais indicados (PI ou Cpx). Os campos sombreados representam as composições dos fenocristais de PI e Cpx. 
indicam, na região estudada, as mesmas condições físicas (i.e. P e T) aluando em um sistema com $\mathrm{P}_{\mathrm{H} 2 \mathrm{O}}$ variável.

Implicações regionais da caracterização de paragêneses granulíticas na Sequência Juscelândia As paragêneses granulíticas descritas neste trabalho têm implicações importantes para o entendimento dos terrenos de alto grau do Brasil central. Embora as condições de metamorfísmo não tenham sido determinadas quantitativamente, as paragêneses de mais alto grau das rochas metavulcânicas máficas do afloramento do rio Pombal são idênticas àquelas observadas em rochas máficas na borda oeste do segmento NS do Complexo Barro Alto. Este fato indica condições de metamorfísmo semelhantes para as rochas plutônicas do Complexo Barro Alto e as rochas supracrustais da Sequência Juscelândia, corroborando a existência de um evento metamóríico progressivo similar ao descrito para a região de Niquelândia (Ferreira Filho et al 1992, 1994, 1998). Por outro lado, a natureza progressiva evidenciada no segmento NS contrasta com a quebra metamórfíca descrita para o contato entre o Complexo Barro Alto e a Sequência Juscelândia no segmento EW (Moraes 1997). Este fato sugere que a supressão tectônica de parte da coluna geológica proposta por Moraes (1997) para o segmento EW não ocorre no segmento NS. Esta observação tem implicações para eventuais correlações estratigráficas que venham a ser propostas para os diferentes segmentos do Complexo Barro Alto e da Sequência Juscelândia. Cabe salientar que diferenças significativas entre a estratigrafia do Complexo Barro Alto nos segmentos NS e EW foram recentemente apresentadas por Ferreira Filho (1998).

Implicações petrológicas da caracterização química dos fenocristais primários $\mathrm{A}$ identificação e determinação da composição química de fenocristais permite refinar os estudos voltados ao fracionamento magmático em séries vulcânicas. Os dados obtidos no afloramento do rio Pombal indicam que plagioclásio e clinopiroxênio participam do fracionamento da Sequência Juscelândia. A Fig. 8 apresenta diagramas de variação para 13 amostras de anfibolito (metavulcânica máfica) e uma amostra de granulito máfico (metavulcânica com estrutura almofadada do rio Pombal) da Sequência Juscelândia na área do Projeto Barro Alto/Quebra-Linha. As análises químicas são apresentadas nos relatórios de Graduação do IG-UnB de 1996. A composição química do granulito máfico do Rio Pombal é semelhante à composição dos anfibolitos, corroborando os dados petrográfícos e de campo que indicam variações na paragênese metamórfica decorrentes de diferentes pressões de $\mathrm{H}_{2} \mathrm{O}$. As variações composicionais observadas (Fig. 8) são compatíveis com o fracionamento de clinopiroxênio e plagioclásio. Este dado estabelece algumas restriç̃es para a composição do magma parental à partir do qual a Sequência Juscelândia evoluiu, assim como para eventuais associações plutônicas de natureza cogenética.

Embora uma avaliação litogeoquímica completa não seja objeto do presente trabalho, cabe ressaltar que a razão $\mathrm{MgO} / \mathrm{MgO}+\mathrm{FeOt}$ das metavulcânicas máficas varia entre 0,29-0,46 indicando composições não compatíveis com magmas primitivos em equilíbrio com olivina do manto. Estes resultados são compatíveis com os teores de En (38-42) e Fs (13-16) dos fenocristais reliquiares de Cpx. Os baixos teores de $\mathrm{Ni}$ (média de $78 \mathrm{ppm}$ ) e $\mathrm{Cr}$ (média de $152 \mathrm{ppm}$ ) das metavulcânicas máficas reforçam a natureza fracionada do vulcanismo basáltico da Sequência Juscelândia em seu segmento norte.

CONCLUSÃO A par das implicações regionais discutidas anteriormente, o trabalho apresenta dois resultados objetivos e inéditos para as sequência vulcano-sedimentares situadas à oeste dos grandes complexos acamadados do Brasil central. O primeiro é a constatação da existência da paragênese Opx $+\mathrm{Cpx}+\mathrm{PI}+\mathrm{Hbl}$ indicativa da fácies granulito na Sequência Juscelândia. O segundo é a natureza fracionada do vulcanismo basáltico da Sequência Juscelândia conforme indicado pela composição dos fenocristais de Cpx e PI.

\section{Agradecimentos}

